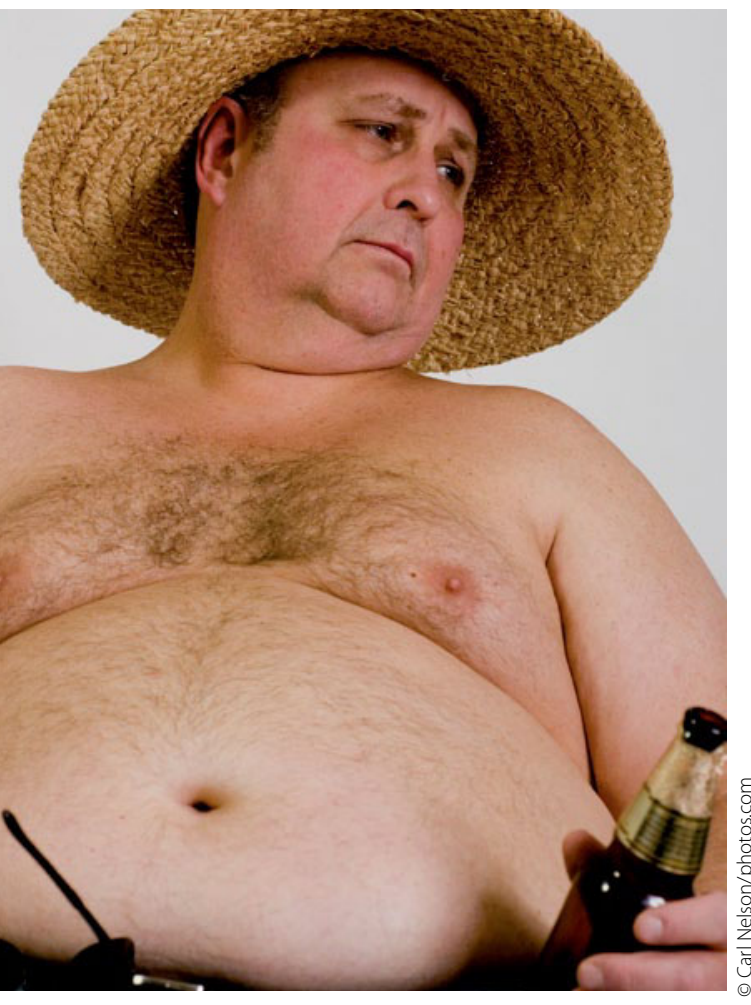

Wird das rechte Maß überschritten, überwiegen rasch die negativen Folgen des Alkoholkonsums.

- Der Alkoholkonsum in Deutschland hat in den letzten Jahren deutlich zugenommen. „Doch der überwiegende Teil der Menschen konsumiert Alkohol nur in moderaten Mengen. Dies gilt auch für Diabetiker", sagte Prof. Michael A. Nauck, Bad Lauterberg. Beim Thema "Alkohol und Diabetes mellitus" stellen sich mehrere Fragen: Kann ein moderater Alkoholgenuss vor der Diabetesmanifestation schützen? Nützt oder schadet ein regelmäßiger Alkoholkonsum bei Diabetikern, und wo liegt die kritische Grenze?

\section{Bier und Wein wirken diabetespräventiv}

Nach den Ergebnissen epidemiologischer Studien kann regelmäßiger Alkoholgenuss das Auftreten eines metabolischen Syndroms verhindern. „Dies gilt jedoch nur für Bier und Wein, aber nicht für Schnaps", so Nauck. Die diabetespräventive Wirkung fand sich insbesondere dann, wenn täglich geringe Mengen an Alkohol genossen wurden. „Die Verhinderung eines Diabetes

Patient mit Diabetes mellitus

\title{
Wie viel Alkohol dürfen Sie ihm erlauben?
}

\author{
Eine strikte Alkoholkarenz ist für die meisten Diabetiker nicht machbar \\ - und auch nicht sinnvoll, denn ein moderater Alkoholkonsum kann \\ durchaus positive Effekte entfalten. So scheinen alkoholische Getränke \\ - in Maßen genossen - diabetespräventiv zu wirken und diabetische \\ Folgeerkrankungen hinauszögern zu können.
}

durch einen gesunden Lebensstil kann durch Alkohol sinnvoll unterstützt werden“, so Nauck. Bei einem hohen Alkoholkonsum von drei oder mehr alkoholischen Getränken pro Tag ist dieser präventive Effekt allerdings nicht mehr nachweisbar. Ab diesen Mengen überwiegen die schädlichen Wirkungen.

\section{Hemmung der Glukoneogenese}

Auch bei bereits manifestem Diabetes mellitus ist ein moderater Alkoholkonsum nicht gesundheitsschädlich; denn Alkohol führt zu einer Verschiebung des intrazellulären Redoxzustandes, wodurch konsekutiv die Glukoneogenese gehemmt wird, was wiederum zu einer vermehrten Laktatbildung führt. „Die unmittelbare Folge eines abendlichen Alkoholgenusses ist daher ein Trend zu niedrigeren Blutzuckerwerten in den frühen Morgenstunden und nach dem Frühstück des folgenden Tages“, so Nauck. Diese Veränderungen seien bei einem Typ-1-Diabetiker ausgeprägter als bei einem Patienten mit einem Typ2-Diabetes.

\section{Erhöhtes Hypoglykämierisiko bei Typ-1-Diabetes}

Zu bedenken ist allerdings: Bei Typ-1Diabtikern kann der Alkoholgenuss die Hypoglykämiewahrnehmung stören. Dazu kommt, dass größere Trinkmengen ungünstigere Verhaltensweisen nach sich ziehen. Dazu gehören eine geringere körperliche Aktivität, eine schlechtere Compliance bezüglich Ernährungsstil, Medikamenteneinnahme und Stoffwechselkontrollen. „Außer- dem rauchen solche Patienten häufiger und stärker“, sagte Nauck.

\section{Koronare Ereignisse verhindert}

Nicht nur bei Diabetikern, sondern auch bei Stoffwechselgesunden kann ein regelmäßiger moderater Alkoholkonsum koronare Ereignisse verhindern und somit die Mortalität senken.

Bei Diabetikern beeinflusst ein moderater Alkoholgenuss auch die diabetischen Folgeerkrankungen günstig. „Moderater Alkoholgenuss reduziert bei Typ-1-Diabetikern das Risiko für eine poliferative Retinopathie, eine Neuropathie und eine Makroalbuminurie“, so Nauck. Auch das Risiko für eine Niereninsuffizienz werde gesenkt.

Aus den vorliegenden Daten kann man zusammenfassend folgern, dass ein moderater Alkoholkonsum weder für Typ-1- noch für Typ-2-Diabetiker gesundheitsschädlich ist. Er ist vielmehr sogar eher von Nutzen. Wegen der Auswirkungen auf den Blutzuckerspiegel muss der Genuss von Alkohol aber in das therapeutische Management einbezogen werden, d. h. die Insulindosierung kann sich ändern.

Eine generelle Empfehlung zum moderaten Alkoholkonsum abzuleiten, ist allerdings wegen der zunehmenden Suchtgefährdung problematisch.

Dr. med. Peter Stiefelhagen -

- Quelle: 46. Jahrestagung der Deutschen Diabetes-Gesellschaft am 2.6.2011 in Leipzig.

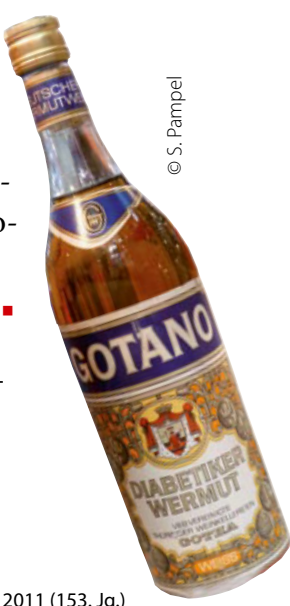

